\title{
The Vogt-Koyanagi-Harada and SAPHO Syndrome: An Unusual Association
}

\begin{abstract}
DRAGOS PALADE ${ }^{1}$, LAURA OTILIA DAMIAN², DOINEL RADEANU ${ }^{3 *}$, ANNE CLAUDIA STEFANUT4, GHEORGHE COBZAC CRISTIAN DRAGOS STEFANESCU6 ${ }^{6}$, ALMA MANIU ${ }^{7}$

${ }^{1}$ Grigore T. Popa University of Medicine and Pharmacy, 16 Univeritatii Str., 700115, Iasi. Romania

Emergency Clinical County Hospital Cluj-Napoca, Rheumatology Department, Centre for Rare Musculoskeletal Autoimmune and Autoinflammatory Diseases, 3-5 Clinicilor Str., 400000, Cluj-Napoca, Romania,

3University of Medicine and Pharmacy Cluj-Napoca, E.N.T. Department, 8 Victor Babes Str., 400012, Cluj-Napoca, Romania ${ }^{4}$ Emergency Clinical County Hospital Cluj-Napoca, Ophtalmology Department, 3-5 Clinicilor Str., 400000, Cluj-Napoca, Romania, ${ }^{5}$ Emergency Clinical County Hospital Cluj, Nuclear Medicine Department, 3-5 Clinicilor Str., 400000, Cluj-Napoca, Romania, ${ }^{6}$ National Institute of Aeronautical and Space Medicine Gen. Dr. Aviator Victor Anastasiu, University of Medicine and Pharmacy Carol Davila, E.N.T. Department, 88 Mircea Vulcanescu Str.,010825, Bucharest, Romania

7Iuliu Hatieganu University of Medicine and Pharmacy Cluj-Napoca, E.N.T. Department, 8 Victor Babes Str., 400012, Cluj-Napoca, Romania
\end{abstract}

Vogt-Koyanagi-Harada syndrome(VKH) is a multisystemic disorder characterized by granulomatous panuveitis and cutaneous, otorhynolaryngologic and neurologic involvement, due to an autoimmune reaction against melanocytic antigens. Autoinflammatory associations of VKH, including inflammatory bowel disease and psoriasis, were rarely described. SAPHO syndrome (an acronym for synovitis, acne, hyperostosis, pustulosis and osteitis) is a rare autoinflammatorymusculo-scheletal disease. This paper reports on a male patient presenting for long-lasting bone and joint pain, dysphagia, having a ten-year history of bilateral optic neuritisw hich required high-dose corticosteroids. Fundoscopy revealed diffuse chorioretinalnonpigmented atrophic lesions. Vitiligo, acne scars, clavicular deformity, recurrent chest pain and sacroiliitis pointed to a long-standing SAPHO syndrome and late-phase VKH. Blood tests found inflammation and anti-hepatitis C antibodies with repeatedly undetectable viremia. Bone scintigraphy with the characteristic bull's head upper chest uptake and the radiographs confirmed SAPHO syndrome. The patient was treated with sulphasalazine and cyclosporin A, with alleviation of the articular and bony disease. In conclusion, SAPHO syndrome may add to the list of the diseases associated with VKH. Although VKH and SAPHO syndrome may have appeared coincidentally, a common pathogenesis involving an infectious trigger and IL-17 could be considered.

Keywords: Vogt-Koyanagi-Harada disease, SAPHO syndrome, autoinflammatory, P. acnes, interleukin-17

VKT is a multisystemic autoimmune disorder directed against melanocytes, characterized by granulomatous panuveitis with exudative retinal detachments, often associated with neurological [1] and cutaneous manifestations [2]. The term SAPHO, coined as an acronym for synovitis, acne, hyperostosis, pustulosis and osteitis, denominates a syndrome characterized by anterior chest wall arthritis, along with bone inflammation and neutrophilic skin pseudo-abscesses [3]. We describe an unusual case of VKH and SAPHO syndrome.

\section{Experimental part}

A 65-year male patient reported to our department witha recent exacerbation of long-lasting joint and bone pain, accompanied by low-grade intermittent fever and a $5-\mathrm{kg}$ weight loss. His history included a bilateral optic neuritis at the age of 45 , when the patient recalled feeling very ill complaining mainly of visual disturbance and headache, but also of chest and joint pain. He had received one year of high-dose prednisone courses, for vision salvage, that also alleviated joint pain. Three months thereafter he developed bilateral hip osteonecrosis, for which he underwent bilateral hip replacement, and noticed patchy symmetric skin discoloration on the extremities diagnosed by dermatologist as vitiligo. J oint and chest pain recurred after stopping corticosteroids. Cardiological and gastroenterological assessments were repeatedly normal. He also developed acne, attributed to corticotherapy, although it seemed to start along with the illness and fluctuated even after corticotherapy cessation.

Our clinical examination revealed vitiligo on the extremities, acne scars on the shoulders and face, a few discrete pustules on the left sole and sensitivity to palpation of clavicles, sternum, left humerus, sacrum and left thigh, as well as a minimal effusion of the left knee. He had no hydrosadenitis history. Ancillary examination showed inflammation (ESR $22 \mathrm{~mm} / \mathrm{h}$; CRP $40.3 \mathrm{mg} / \mathrm{dL}$, range $0-5$ $\mathrm{mg} / \mathrm{dL}$; fibrinogen $428 \mathrm{mg} / \mathrm{dL}$, range $200-400 \mathrm{mg} / \mathrm{dL}$ ), negative $\mathrm{HLA}-\mathrm{B} 27$, as well a positive anti- hepatitis $\mathrm{C}(\mathrm{HCV})$ autoantibody test, with a non-detectable HCV viremia (realtime PCR, detection limit under $15 \mathrm{lU} / \mathrm{mL}$ ), negative hepatitis B and HIV tests and a FibroTest score F0. Bone scintigraphy (Fig.la, b) showed sternoclavicular and upper chest enhancement, as well as increased sacroiliac uptake. Bone radiographs revealed a left femoral shaft osteitis.

The ophtalmoscopic examination with fundoscopy revealed chorioretinal depigmented lesions, well defined, whitish, located intermaculo-papillary in the right eye (Fig. 2 , a) and paravascular, in the middle of retinal periphery in the lefteye (Fig. 2, b), with normal appearance of the retinal vessels. There was also temporal pallor of papilla in the right eye. Otorhynolaryngologic examination show dysphagia and tinnitus.

*email:doinel.radeanu@gmail.com, doinel.radeanu@umfcluj.ro 

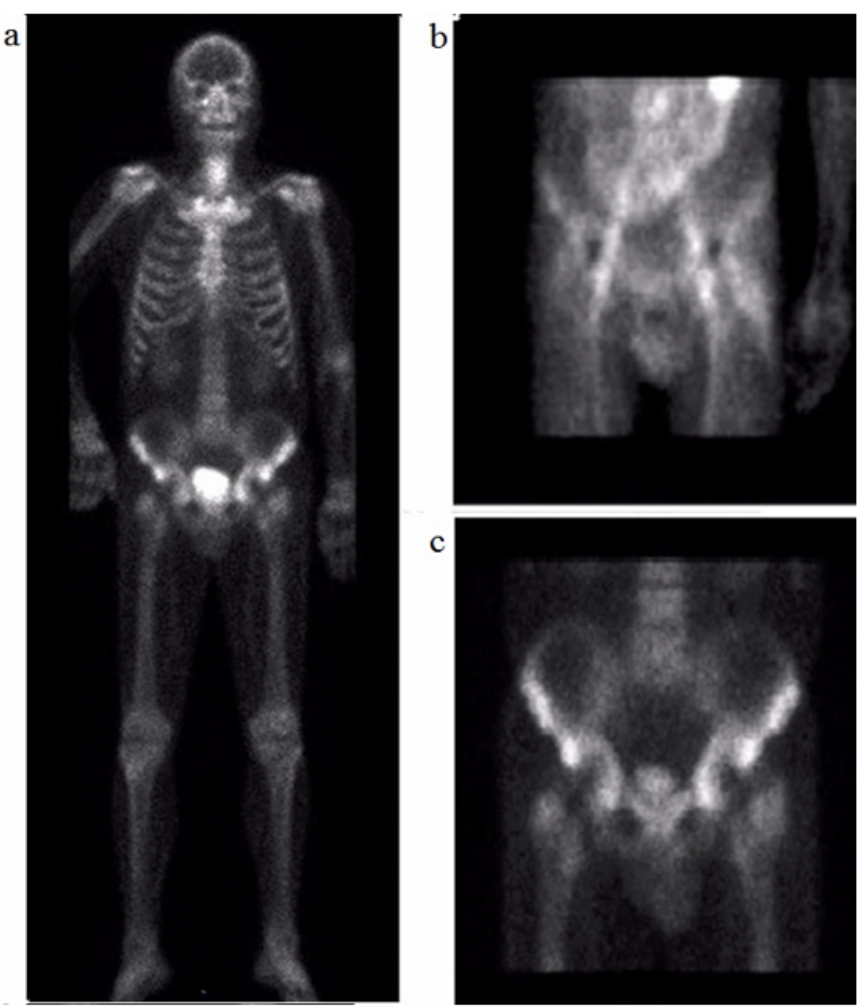

Fig.1. Bone scintigraphy (99mTc-HDP, 3-phases, $600 \mathrm{mBq}$ administered dose) showing the typical manubrium and sternoclavicular uptake (the bull's head sign) (a), and sacroiliac enhancement anterior view (b), posterior view (c).
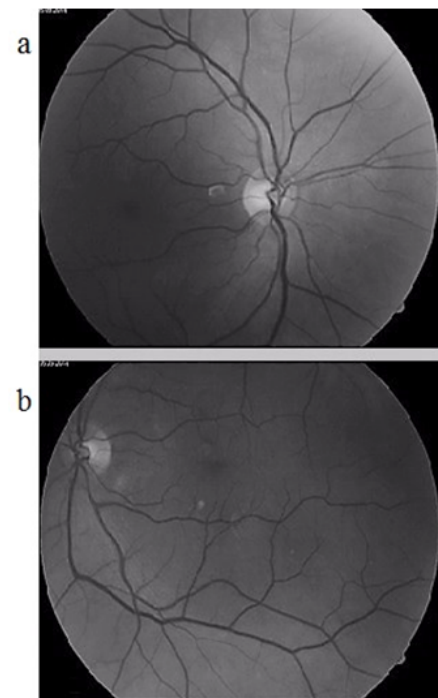

Fig. 2. (a)right-eye ophtalmoscopy: chorioretinal depigmented, lesions, well-defined, whitish, intermaculo- papillary, temporal

pallor of the papilla, with normal appearance of the retinal vessels;(b) left-eye ophthalmoscopy:chorioretinal depigmented, lesions, well-defined, whitish, paravascular, in the middle of the retinal periphery, with normal appearance of the retinal vessels.

Ourdiagnosewas SAPHO syndrome, along with a VKH syndrome in late post-inflammatory phase. The therapy consisted ofsulphasalazine with an incomplete response, to which cyclosporine was latter added. This led to a net improvement of the joint symptomatology and maintenance of the ocular aspect.

\section{Results and discussions}

VKH is a rare multisystemic inflammatory granulomatous disorder in genetically susceptible individuals affecting pigmented structures - eye, meninges, internal ear, skin and hair [2]. Usually after a viral trigger, granulomatous panuveitis occurs along with systemic signs as vitiligo, poliosis, hearing loss, tinnitus or central nervous system involvement[2]. Late manifestations of VKH include evidence of previous early manifestations with ocular depigmentation and nummular chorioretinal scars, retinal pigmentar epithelium clumping and migration or anterior uveitis[1]. The patient metthe criteria for late VKH, having vitiligo, chorioretinal scars and relevant ophtalmologic history.

Various autoimmune associations of VKH syndrome have been reported, including polyglandular autoimmune syndrome type I, Hashimoto thyroiditis etc.[2]. Autoinflammatory diseases have been also ocasionally described in VKH, including ulcerative colitis, Crohn's disease, psoriasis or reactive arthritis[4-7]. However, the association of VKH with SAPHO (recently classified as autoinflammatory) or its juvenile variant chronic recurrent multifocal osteitis (CRMO) has notbeen previously reported, to the best of our knowledge.

SAPHO syndrome is a rare and probably underestimated disease, encompassing a variety of osteoarticular disorders involving the upper chest and accompanied by acne, palmo-plantar pustulosis or hidradenitis suppurativa[3]. Plantar pustules in SAPHO are undistinguishable from pustulous psoriasis, and most cases of CRMO and SAPHO evolve into spondylartritis over long term $[3,8,9]$. Radiographs may show osteitis, osteolysis healing with sclerosis and hyperostosis. The whole-body scintigraphy reveals increased tracer uptake in the sterno-costoclavicular region (the bull's head sign) and also clinically silent lesions[3].

The association of SAPHO and VKH has not been reported to the best of our knowledge. However, in Akita dog breed,the animal model of VKH, a sebaceous adenitis was found, among other autoimmune diseases[7].

SAPHO is often regarded as a reactive infectious osteitis to P.acnes [10]. P. acnes is a commonly found skin saprophyte, an aerotolerant anaerobic Gram- positive bacillus with low virulence, causing acne[10]. Of note, $P$. acnes was found in lesional areas of progressive macular hypomelanosis[ 11] and has been involved in lens-induced granulomatous uveitis[12], besides keratitis, ulcers and delayed endophtalmitis [13]. P. acnes survival in macrophages explains its role in granuloma formation[14]. $P$. acnes induces Toll-like receptors (TLRs), that link innate and acquired immunity [15]. In VKH, TLR3 and TLR4 trigger the production of proinflammatorycitokines and reactive oxygen species[16]. P. acnes is also a potent inductor of IL-17, which amplifies the recruitment of neutrophils and monocytes[17]. IL17, produced mainly by T cells, is involved in VKH, as well as in SAPHO pathogenesis[19].

The patient also had a healed HCV infection, with elevated anti-HCV antibodies and negative viremia and normal liver enzymes and hepatic tests. Notably, hepatitis $\mathrm{C}$ was associated with VKH, but mainly in the setting of pegylated interferon -alpha $2 \mathrm{~b}$ and ribavirin therapy[20]. The patient received sulphasalazine associated with cyclosporine. The therapy of VKH consists in corticosteroids, with early- introduced immunosuppression and biologics, including anti-TNF and possibly anti-IL17 agents[2] .

\section{Conclusions}

SAPHO syndrome may add to the list of autoinflammatory syndromes associated with VKH. Although VKH and SAPHO syndromes may have appeared coincidentally, a common pathogenesis could be considered, including IL17 activation, as a possible therapeutic target. 
Informed consent was obtained from the patient whose information is included in this article.

Abbreviations: CRMO- chronic recurrent multifocal osteitis; HCVhepatitis C virus; IL-17- interleukin 17; SAPHO-synovitis, acne, hyperostosis, pustulosis, osteitis syndrome;TLR- Toll-like receptor; VKH-Vogt-Koyanagi-Harada syndrome

\section{References}

1.READ RW, HOLLAND GN, RAO NA, TABABARA KF, OHNO S, ARREANE-GARCIA L et al: Am J Ophtalmol, 131 (5), 2001, p. 647. 2.LAVEZZO MM, SAKATA VM, MORITA C, RODRIGUEZEEC, ABDALLAH SF, DA SILVA FTG, HIRATA CE, YAMAMOTO YH.: Orphanet] Rare Dis,11, 2016, p. 29.

3.NGUYEN MT, BORCHERS A, SELMI C, NAGUWA SM, CHEMMA G, GERSHWIN ME: SeminArthr Rheum,42, 2012, p. 254.

4.DE LA POZA GOMEZ G, LOPEZ-SAN ROMAN A, MASJ UAN VALLEJ O J et al:GastroenterolHepatol,32, 2009, p. 343.

5.SOUGUIR A, HAMMAMI A, DAHMENI W, JAZIRI H, BEN MASOUR I, ZAYENE A et al: Gastroenterol Rep doi: 10.1093/gastro/gov056, 2015. 6.PAROLI MP, PINCA M, SPERANZA S, PIVETTI-PEZZI P: Ocular Immunollnflamm,11(4), 2004, p. 309.

7.EMAD Y, RAGAB Y, RASKER J]: The Egyptian Rheumatologist,35(4), 2013, p. 249.

8.HEDRICH CM, HOFFMANN SR, PABLIK J, MORBACH H, GIRSCHICK HJ : PediatrRheumatol Online J ,11, 2013, p. 47.
9.VITTECOQ 0, SAID LA, MICHOT C, MEJJAD O, THOMINE J M, MITROFANOFF P et al: Arthritis Rheum,11, 2000, p. 109.

2ROZIN AP.: Arthritis Res Ther,11(6), 2009, p.131.

10.CAVALCANTI SMM, DE FRANCA ER, MAGALHAES M, LINS AK, BRANDAO LC, MAGALHAES V:Braz J Microbiol,42(2), 2011, p. 423.

11.SEMEL J, BOWE B, GUO J, RIFE L, POLIKOFF D et al:Investigative Ophtalmol Visual Sci,33(5), 1992, p. 1766.

12.OVODENKO B, SEEDOR JA, RITTERBAND DC, SHAH M, YANG R, KOPLIN RS: Cornea 28(1), 2009, p. 36.

13.FISCHER N, MAK TN, SHINOHARA DB, SFANOS KS, MEYER TF, BRUGGEMANN H: Biomed Res Internat,2013.

14.J UGEAU S, TENAUD I, KNOL AC, JARROUSSE V, QUEREUX G, KHAMMARI A, DRENO B: Br J Dermatol,153(6), 2005, p. 1105.

15.LIANG L, TAN $X$, ZHOU Q, TIAN Y, KIJ LSTRA A, YANG P: Curr Mol Med,15(6), 2015, p. 529.

16.AGAK GW, QIN M, NOBE J, KIM MH, KRUTZIK SR, TRISTAN GR, ELASHOFF D, GARBAN HJ, KIM J : J Invest Dermatol,134(2), 2014, p. 366.

17.WANG C, TIAN Y, LEI B, XIAO X, YE Z, LI F, KIJ LSTRA A, YANG P: Invest Ophtalmol Vis Sci,53(8), 2012, p. 4668, doi: 10.1167/iovs.129863.

18.FIRINU D, GARCIA-LARSSEN V, MANCONI PE, DEL GIACCO SR-: CurrRheumatol Rep 18, 2016, p. 35,doi 10.1007/s11926-016-0583$\mathrm{y}$.

19.TOITOU V, BODAGHI B, CASSOUX N, TRAN TH, RAO NA, CACOUB P, LEHOANG P-:Am J Ophtalm,140(5), 2005, p. 949.

Manuscript received:29.04.2019 